\title{
Article \\ Comparative Study of Corrosion Properties of Different Graphene Nanoplate/Epoxy Composite Coatings for Enhanced Surface Barrier Protection
}

\author{
Randy Raymond Abakah D, Feng Huang, Qian Hu, Yicong Wang and Jing Liu* \\ State Key Laboratory of Refractories and Metallurgy, Wuhan University of Science and Technology, \\ Wuhan 430081, China; randyraymond90@yahoo.com (R.R.A.); huangfeng@wust.edu.cn (F.H.); \\ huqian@wust.edu.cn (Q.H.); Onion_YicongWANG@outlook.com (Y.W.) \\ * Correspondence: liujing@wust.edu.cn; Tel.: +86-27-6886-2288
}

check for updates

Citation: Abakah, R.R.; Huang, F.; Hu, Q.; Wang, Y.; Liu, J. Comparative Study of Corrosion Properties of

Different Graphene

Nanoplate/Epoxy Composite Coatings for Enhanced Surface Barrier Protection. Coatings 2021, 11, 285. https://doi.org/10.3390/ coatings11030285

Academic Editor: Cecilia Bartuli

Received: 1 February 2021

Accepted: 25 February 2021

Published: 1 March 2021

Publisher's Note: MDPI stays neutral with regard to jurisdictional claims in published maps and institutional affiliations.

Copyright: (c) 2021 by the authors. Licensee MDPI, Basel, Switzerland. This article is an open access article distributed under the terms and conditions of the Creative Commons Attribution (CC BY) license (https:/ / creativecommons.org/licenses/by/ $4.0 /)$.

\begin{abstract}
Loading of graphene to polymeric materials has proven a widespread increase in the corrosion properties of nanocomposites. In this study, graphene nanoplatelets (Gnps)/epoxy composite coatings were prepared by incorporating three commercial graphene nanoparticles (C750, M15, and X50 Gnps) into epoxy resin. The morphological impact of the Gnps on the surface barrier protection were evaluated in terms of coating's adhesion to the substate, hydrophobicity and water uptake performance. Salt spray resistance and Electrochemical Impedance Spectroscopy (EIS) authenticated that the coating integrated with C750 Gnp remarkably improved the anti-corrosion performance of neat epoxy composite coatings. A robust passive layer and surface barrier characteristics formed by the composite coatings incorporated with C750 nanoparticle should be the main reason for better protection properties offered by $\mathrm{C} 750 \mathrm{Gnp} /$ epoxy nanocomposites. At the same time, homogeneous dispersion and lesser agglomerates in $\mathrm{C} 750 \mathrm{Gnp} /$ epoxy composite coatings mainly contributed to the coating's excessive corrosion resistance.
\end{abstract}

Keywords: graphene nanoplates; epoxy; composite coating; surface barrier properties; corrosion protection

\section{Introduction}

The problem of metal corrosion has existed since time immemorial, and several attempts have been made to boost the corrosion resistance of metals. Among numerous corrosion protection methods, organic coatings (epoxy based) have gained much interest due to higher corrosion resistance and outstanding adhesion to metallic substrates [1-3]. Nevertheless, epoxy coatings frequently face durability issues such as surface blistering and delamination which is mainly caused by the micro-pores formed during the curing stage of neat epoxy thereby leading to a significant decline in its barrier performance [4,5]. To help curb this problem, many researchers have tremendously tried incorporating nanoparticles in epoxy matrix to enhance its performance. Latterly, $\mathrm{Al}_{2} \mathrm{O}_{3}$ [6], $\mathrm{SiO}_{2}$ [7], $\mathrm{Ti}[8], \mathrm{ZnO}[5,9]$, $\mathrm{Fe}_{2} \mathrm{O}_{3}$ [10], $\mathrm{TiO}_{2}$ [11], and graphene nanoplatelets (Gnps) [12] are the most used nanoparticles. Gnps has particularly attained the foremost interest for nanoparticles owing to their exceptional barrier properties [13,14]. Moreover, high specific surface area of Gnps leads to an improved interfacial interaction between the Gnps and the polymeric matrix [14,15]. Additionally, an outstanding electrical, mechanical, thermal conductivity, chemical resistance, hydrophobic nature and impermeability of Gnps proves a greater potential of enhancing the ant-corrosion resistance properties of epoxy composites [16-18].

Recently, several studies have been conducted on epoxy composite coating's performance incorporated with different nanofillers in various industrial fields $[19,20]$. For this reason, how Gnps influence the corrosion protection properties of epoxy coatings and its relation to surface barrier improvements is widely investigated. For example, Monetta 
et al. [21] experimented on the impact Gnps have on epoxy coating's performance. Their results advised that Gnps improved the corrosion properties of epoxy. In essence, Silvia [22] lately reported that the barrier properties of Gnps/epoxy composites strongly depend on their thickness and lateral dimension in that, a high specific surface area increases corrosion resistance of epoxy coatings once Gnps are uniformly dispersed. Furthermore, the surface barrier properties of Gnps/epoxy coatings have been proven to vary reckoning on the dissimilar topographical features of different Gnp sheets [23]. Liu et al. [24] discussed the corrosion properties of epoxy coating reinforced by graphene nanoparticles. They disclosed that agglomeration of the nanoparticles caused the coating's surface degradation. On the opposite hand, some authors have also reported on the physical properties of graphene epoxy composite coatings. Satarkova et al. [25] investigated the water uptake performance of composites coatings and concluded that free volume and restriction of polymer chains surrounding the Gnps influenced water absorption. Similarly, Jun [26] evaluated the properties of graphene loaded water-based epoxy coating and discussed that, the presence of graphene did not affect the coating's adhesion to the metallic substrate but however enhanced the hydrophobic characteristics of the coatings. In fact, it is also proven in recent studies that metal substrates can be well protected by graphene/epoxy films that play a role of physical barrier against corrosion. These findings have been confirmed by some electrochemical measurements indicating that graphene/epoxy coatings hinder the formation of corrosion products [27].

Although Gnps addition in epoxy composite coating has been in the limelight in the field of nano materials, few papers these days addressed Gnps effective utilization and developmental progress with the purpose of enhancing the surface barrier properties of composite coatings against corrosion $[5,12,24]$. However, the diverse morphological influence of distinct Gnps on the physical surface barrier properties and anti-corrosion protection mechanism of epoxy composite coatings is nevertheless not widely known to the best of our knowledge. In this study, three different commercial Gnps (C750, M15 and X50) with different morphological features were used to prepare Gnps/ epoxy composite coating. Field Emission Scanning Electron Microscopy (FE-SEM), Energy-Dispersive XRay Spectrum (EDS) and Optic/Stereoscopic Microscopy were used to characterize the morphology, composition and dispersion characterization of the coatings. Water uptake testing, salt spray testing and electrochemical measurements such as electrochemical impedance spectroscopy (EIS) were employed to determine and analyze the anti-corrosion and water uptake performance of the prepared coatings. The influence mechanism of Gnps on epoxy coating's anti-corrosion performance was analyzed.

\section{Experimental}

\subsection{Materials}

Three different commercial graphene nanoparticles (C750, M15 and X50) were purchased from XG Sciences Inc (Lansing, MI, USA). The physical properties of the Gnps used in this study as provided by the manufacturer is shown in Table 1. The epoxy resin (diglycidyl ether of bisphenol A, E-51) and its Ethylenediamine Hardener were supplied by Shanghai Jiuqing Chemical Co., Ltd (Shanghai, China).

Table 1. Physical properties of commercialized Gnps used in this study.

\begin{tabular}{ccc}
\hline Grade & Diameter $(\mu \mathrm{m})$ & Specific Surface Area $\left(\mathbf{m}^{2} \mathbf{g}^{-1}\right)$ \\
\hline C750 Gnp & $<2$ & $\sim 750$ \\
M15 Gnp & $<15$ & $\sim 150$ \\
X50 Gnp & 150 & $50-80$ \\
\hline
\end{tabular}

\subsection{Preparation of Gnps/Epoxy Coatings on Steel Samples}

Chinese GB standard Q235B (DIN EN S235JR European standard) [28] with a chemical composition of (wt.\%): C 0.14, Si 0.19, Mn 0.31, P 0.015, S 0.0024, Cu 0.016, and Fe was 
used as the main substrate. All samples were immersed in a $\left(\mathrm{H}_{2} \mathrm{O}: \mathrm{HCl}\right.$ : methacrylic acid $)$ solution in a ratio of 5:5:1 to remove rust, grounded with (180, 240, 400 and 600) grit abrasive $\mathrm{SiC}$ papers, cleaned in acetone for $5 \mathrm{~min}$, washed with distilled water and dried in high-purity nitrogen $(99.999 \%)$ awaiting to be coated. Pure epoxy coatings were prepared via mechanically mixing epoxy resin and Hardener in the ratio of 3:1. The mixture was degassed in a bath sonicator, coated on the steel substrate and allowed to dry for $24 \mathrm{~h}$ at room temperature. To prepare the Gnps/epoxy composite coatings, 1 wt. $\%$ of Gnps were added to a measured volume of dimethyl formamide solvent (DMF), ultrasonically dispersed to exfoliate the Gnp sheets in the epoxy matrix with an ultrasonic machine (Ningbo Scientz Biotechnology Co., Ltd (Ningbo, China) at a power of $380 \mathrm{~W}$ for $30 \mathrm{~min}$, then vacuum filtered to obtain wet Gnps. According to 4:1 ratio of epoxy and Hardener, a mixed solvent was prepared with the wet Gnps previously obtained. The Gnps/epoxy mixture was ultrasonicated with a power of $100 \mathrm{~W}$ for $20 \mathrm{~min}$ and then stirred magnetically for $2 \mathrm{~h}$. Finally, the prepared composite coatings were vacuum degassed for $10 \mathrm{~min}$, brushcoated onto the previously prepared steel substrates and allowed to cure for 7 days at room temperature for subsequent test observations. To ensure that the coating layer is of a uniform thickness throughout, good brushing techniques and a flat level surface were employed. Also, the coating was applied liberally and spread uniformly, followed by a criss-crossing action with the brush. The thickness of the dried coatings was measured to be $100 \pm 20 \mu \mathrm{m}$ by sndway SW-6310C coating thickness meter (Shenzhen, Guangdong, China). Figure 1 shows the schematic preparation of the graphene epoxy nanocomposites coatings.

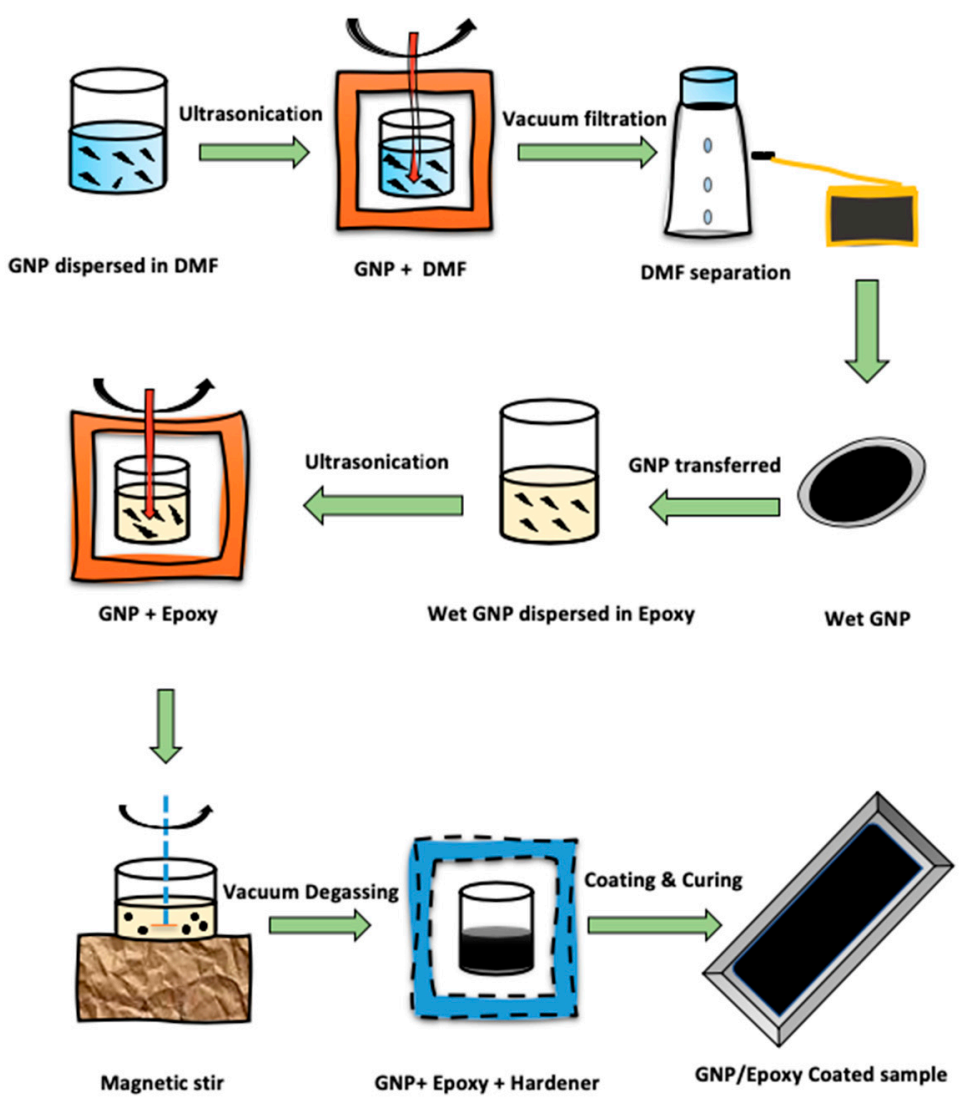

Figure 1. Schematic diagram of the preparation of graphene nanocomposites.

\subsection{Characterization of Gnps/Epoxy Composite Coatings}

Optical and stereoscopic 3D microscopic images with magnification $200 \times$ and $1000 \times$ (Bell MPL-1, VHX-500 KEYENCE, Itasca, IL, USA) were taken to investigate the homogeneous distribution of Gnps in epoxy coatings. FE-SEM (ZEISS, Jena, Germany) with 
20,000 $\times$ magnification and EDS were used to confirm the different morphologies of Gnps and elemental composition of the coatings respectively.

\subsection{Pull-Off Adhesion Testing}

In order to investigate the coating's adhesion strength, a pull off adhesion test according to ASTM 4541 standards [29] was employed. All samples were prepared with same procedure as described in Figure 1. Aluminum test dollies $\left(0.5 \mathrm{~cm}^{2}\right)$ were glued to the coated surface with a two-part Araldite 2015 adhesive glue and allowed to cure for $48 \mathrm{~h}$ at room temperature. Elcometer 108 adhesion of maximum applied load of $20 \mathrm{MPa}$ tester was used. The pull-off strength loss values were calculated by the equation:

$$
\text { The pull }- \text { off strength } \% \text { loss }=\frac{a-b}{a} \times 100 \%
$$

where $a$ and $b$ are dry pull-off strength and wet pull-off strength (7 days of immersion in $3.5 \% \mathrm{NaCl}$ solution) respectively. All measurements were done in triplicate.

\subsection{Water Contact Angle and Absorption Testing}

Coating's hydrophobicity was investigated by water contact angle (WCA) test using an OCA 15 EC (DataPhysics Instruments GmbH, Filderstadt, Germany) according to ASTM D7490 [30]. Droplets of water of $0.2 \mathrm{~mL}$ were carefully dispensed on the surface of the samples. The obtained WCA was evaluated on an average of 10 measurements taken on different points on the coating surface. Water absorption $\left(Q_{w}\right)$ testing was conducted on epoxy and Gnps/epoxy coatings (thickness of $100 \pm 10 \mu \mathrm{m}$ ). The formula below was used to determine the amount of water absorbed by the samples.

$$
Q_{w}=\frac{m_{t}-m_{i}}{m_{i}} \times 100 \%
$$

where $m_{t}$ and $m_{i}$ are the mass of the coating before and after water absorption, respectively, and $t$ representing the immersion time. Three parallel samples were used for all coating types for accurate evaluation. All coated samples were deeply immersed in distilled water without oxidation. Prior to measurement, samples were dried with a non-woven fabric to remove excess water on the surface. The mass of the coated samples was measured with a microbalance of $0.00001 \mathrm{~g}$ accuracy. The experiment was conducted over a 15-day period.

\subsection{Salt Spray Testing}

The corrosion properties of the Gnps/epoxy coatings were studied by salt spray testing. Coated samples $5 \mathrm{~mm} \times 75 \mathrm{~mm} \times 140 \mathrm{~mm}$ were put in a Q-FOG Cyclic Corrosion Tester (Q-Lab, Buckeye, AZ, USA). Prior to testing, the coated samples were X-cut $120 \mathrm{~mm} \times 0.8 \mathrm{~mm}$ and exposed to $5 \% \mathrm{NaCl}$ fog (pH of 6.5-7.2 and temperature of 35 ${ }^{\circ} \mathrm{C}$ ) for $750 \mathrm{~h}$ according to ASTM B117 standards [31]. After testing, ISO $4628-1: 2016$ standards [32] was used to assess coating's performance.

\subsection{Electrochemical Experiments}

EIS measurements were performed using an Auto Lab PGSTAT302F (Metrohm, Switzerland) on a three-electrode cell, with coated steel specimen $\left(1 \mathrm{~cm}^{2}\right.$ in area) as the working electrode, saturated calomel electrode (SCE) as reference electrode, and Pt electrode as counter electrode. The EIS was conducted for 28 days with a potential disturbance of $\pm 20 \mathrm{mV}$ within the frequency range of $0.01-10^{5} \mathrm{~Hz}$ at a rate of 10 points per decade and testing temperature was about $25^{\circ} \mathrm{C}$. The impedance data was processed with Nova 2.1 software (Version 2.1.4). To ensure reproducibility, three tests were performed under each condition. 


\section{Results \\ 3.1. Characterization of Gnps/Epoxy Composite Coatings}

Figure 2 shows the FE-SEM images of the three Gnps under identical magnification. By observation, the shape morphology of all Gnps were unidentical. C750 Gnp seemed lumpy and irregular with globe-like structure (Figure 2a). M15 Gnp showed a stacked structure with discontinuous scrambled surface made up of several spongy layers (Figure $2 b$ ) whiles X50 Gnp appeared as tiny uneven spherical particles entangled in an intertwined netlike structure (Figure 2c). However, the physical properties of the Gnps matches with the reported data from the manufacturer mentioned in the experimental section. Moreover, the actual size distribution of the different Gnps can easily be distinguished by their appearance in Figure 2.

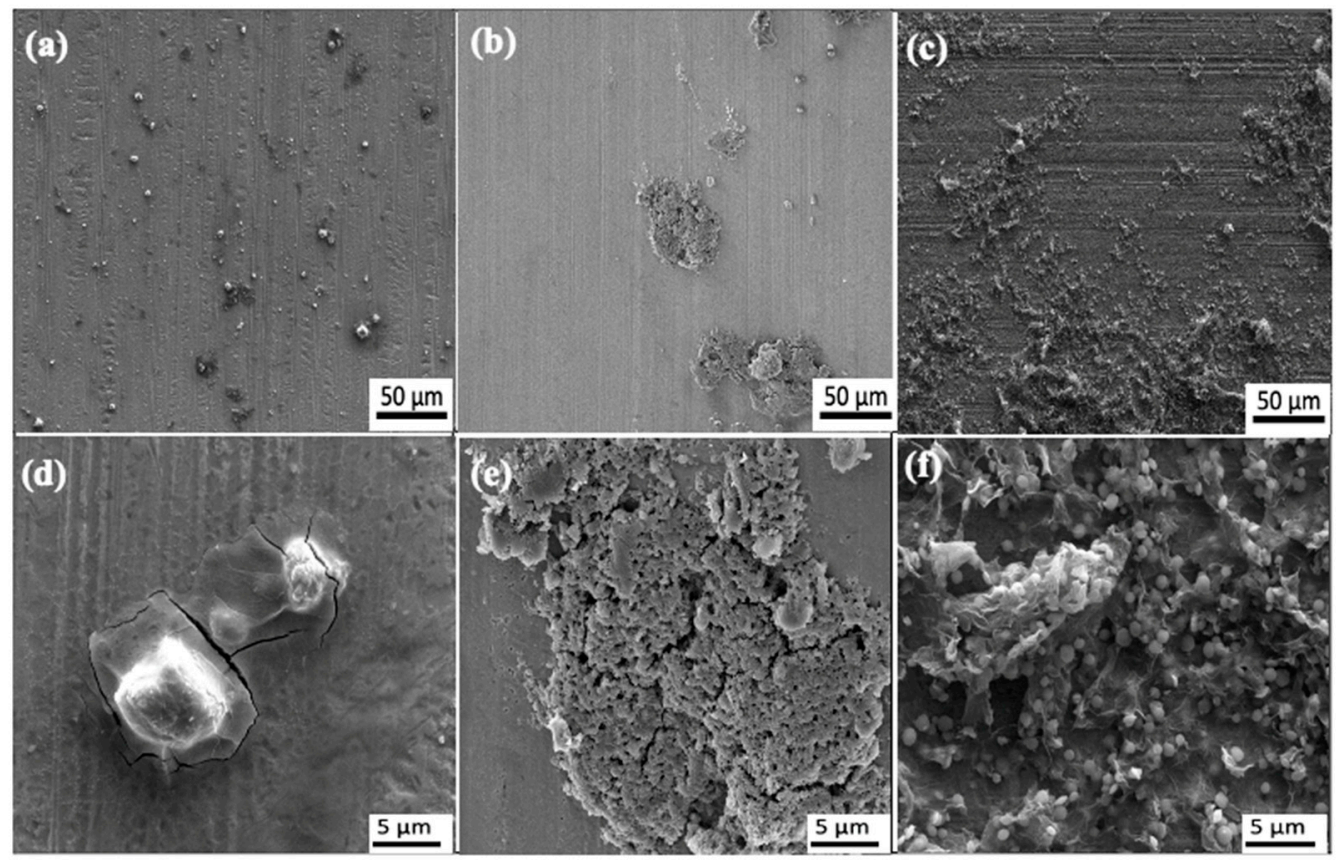

Figure 2. SEM morphology of the Gnps, (a-c): low magnification, (d-f) high magnification, (a,d) C750 Gnp, (b,e) M15 Gnp, (c,f) X50 Gnp.

Figure 3 demonstrates the FE-SEM images of the surface morphology of the prepared Gnps/epoxy composite coatings and their EDS spectra. From the EDS spectra, elements such as $\mathrm{C}, \mathrm{O}, \mathrm{Al}$, and $\mathrm{Si}$ were present in the Gnps/epoxy coatings (Figure 3d). Specifically, the $\mathrm{C}$ and $\mathrm{O}$ elements depict the presence of grapheme, whereas $\mathrm{Si}$ and $\mathrm{Al}$ are characteristic of epoxy which is consistence with [33]. It is clear that each coating possessed a peculiar dispersion morphology in the epoxy composite. For instance, C750 Gnp (Figure 3a) seemed homogeneously dispersed by exhibiting lesser agglomeration and aggregation. The homogenous dispersion can be attributed to the easy interaction with the epoxy matrix due to C750 Gnps high surface area and smaller size [34,35]. Contrarily, M15 and X50 Gnps (Figure $3 b, c$ ) were poorly dispersed with lots of agglomerates randomly formed. This is due to the poor interfacial interactions and weak intermolecular van der Waals forces between the Gnps and the epoxy matrix [36]. The dispersion of Gnps in epoxy coatings were also investigated at microscale using optical and stereoscopic microscopic images (in Figure 4). It is identified that, the C750 Gnp particles are greatly dispersed than the others (Figure $4 \mathrm{a}-\mathrm{c}$ ). For comparison, the Stereoscopic microscopic (SM) images obtained further confirmed a similar dispersion of Gnps observed in the Optic miscroscopic (OM) images (Figure $4 \mathrm{~d}-\mathrm{f}$ ). 


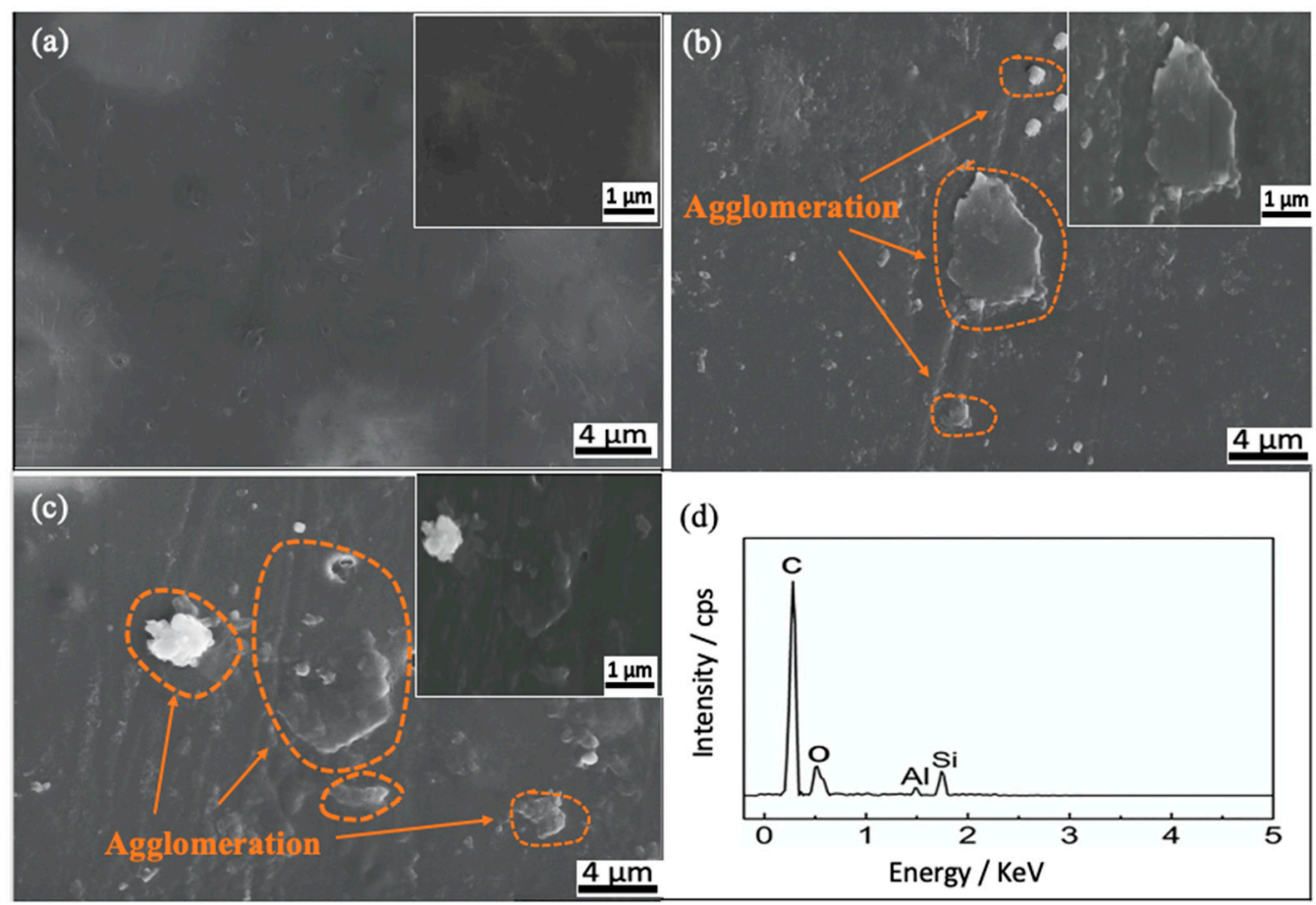

Figure 3. SEM images of the surface morphology of (a) C750 Gnp/epoxy, (b) M15 Gnp/epoxy, (c) X50 Gnp/epoxy coatings at low and high magnification as well as EDS spectra (d) measured at different points.

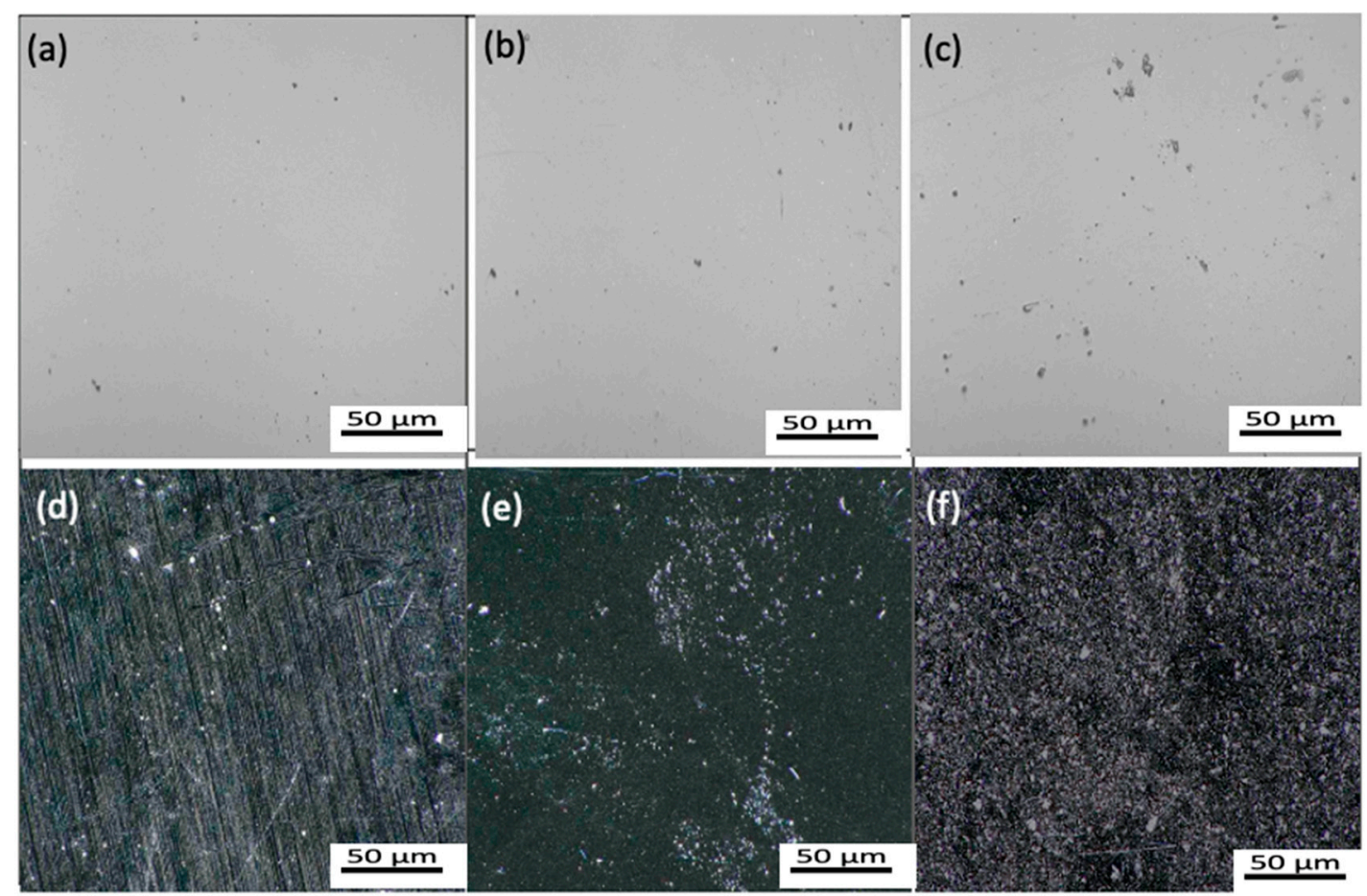

Figure 4. OM images of the dispersion morphology of (a) C750 Gnp/epoxy, (b) M15 Gnp/epoxy and (c) X50 Gnp/epoxy and SM images of (d) C750 Gnp/epoxy, (e) M15 Gnp/epoxy and (f) X50 Gnp/epoxy composite coatings.

\subsection{Physical Properties of Gnps/Epoxy Composite Coatings}

3.2.1. Adhesion Testing

Table 2 shows the adhesion results of neat epoxy and Gnps/epoxy coatings after $170 \mathrm{~h}$ immersion in $3.5 \% \mathrm{NaCl}$ solution. All measurements were done in triplicate and 
the average pull-off strength values were determined. It is discovered that the neat epoxy experienced a higher percentage loss of $37 \%$ but when Gnps were added, the percentage loss reduced confirming an improved adhesion property of the epoxy coatings. Among the three Gnps, C750 Gnp recorded the least percentage loss (9.6\%) followed by M15 Gnp $(14.6 \%)$ and X50 Gnp (19\%) as shown in (Table 2). Moreover, Figure 5 demonstrated that the coating's detachment from the surface of the bare steel was caused by the combination of adhesive and cohesive failures. The cohesive failure happens when the coatings adhesion bond to the steel surface is strong enough that the applied force overcomes the cohesive properties of the coating. On the other hand, when the interfacial adhesion bonds are not so strong the adhesion failure takes place. All prepared Gnps/epoxy coatings adhered much stronger to the substrate than the neat epoxy during both dry and wet testing, however, the overall adhesion loss percentage of C750 Gnp/epoxy coating was much improved as compared to M15 and X50 Gnp/epoxy coatings.

Table 2. Pull-off test results for Gnps/epoxy coatings after 7 days exposure to $3.5 \% \mathrm{NaCl}$ solution.

\begin{tabular}{ccccc}
\hline Coating Sample & Neat epoxy & C750 Gnp & M15 Gnp & X50 Gnp \\
\hline Dry pull-off strength (MPa) & 5.99 & 9.42 & 6.78 & 6.90 \\
Wet Pull-off strength (MPa) & 3.77 & 8.51 & 5.79 & 5.54 \\
Pull-off strength \% loss & $37 \%$ & $9.6 \%$ & $14.6 \%$ & $19 \%$ \\
\hline
\end{tabular}

\begin{tabular}{|c|c|c|c|c|}
\hline Coatings & Neat Epoxy & C750 & M15 & $\mathbf{X 5 0}$ \\
\hline $\begin{array}{c}\text { Dry } \\
\text { Conditions }\end{array}$ & & & & \\
\hline $\begin{array}{c}\text { Wet } \\
\text { Conditions }\end{array}$ & & & & \\
\hline
\end{tabular}

Figure 5. Optical images of epoxy and Gnps/epoxy composite coatings under dry and wet conditions of pull-off adhesion testing against of time.

\subsubsection{Water Contact Angle Testing}

Figure 6 shows the water contact angle values of the neat epoxy and Gnps/epoxy coatings. Generally, coating's hydrophobic nature can be evaluated when the contact angle is determined. Coatings with contact angle less than $90^{\circ}$, greater than $90^{\circ}$, and above $90^{\circ}$ are classified as hydrophilic, hydrophobic and super hydrophobic respectively. In this study, the contact angle value of the neat epoxy coating was $64^{\circ}$ confirming epoxy's hydrophilic nature. X50 Gnp/epoxy, M15 Gnp/epoxy and C750 Gnp/epoxy recorded contact angles of $72^{\circ}, 81^{\circ}$, and $102^{\circ}$ respectively indicating a significant change in the surface roughness of the neat epoxy after adding Gnps. The rise in the contact angle can be linked to the hydrophobic properties of the different Gnps which influenced the coatings tendency to reduce the amount of water uptake on the surface. 

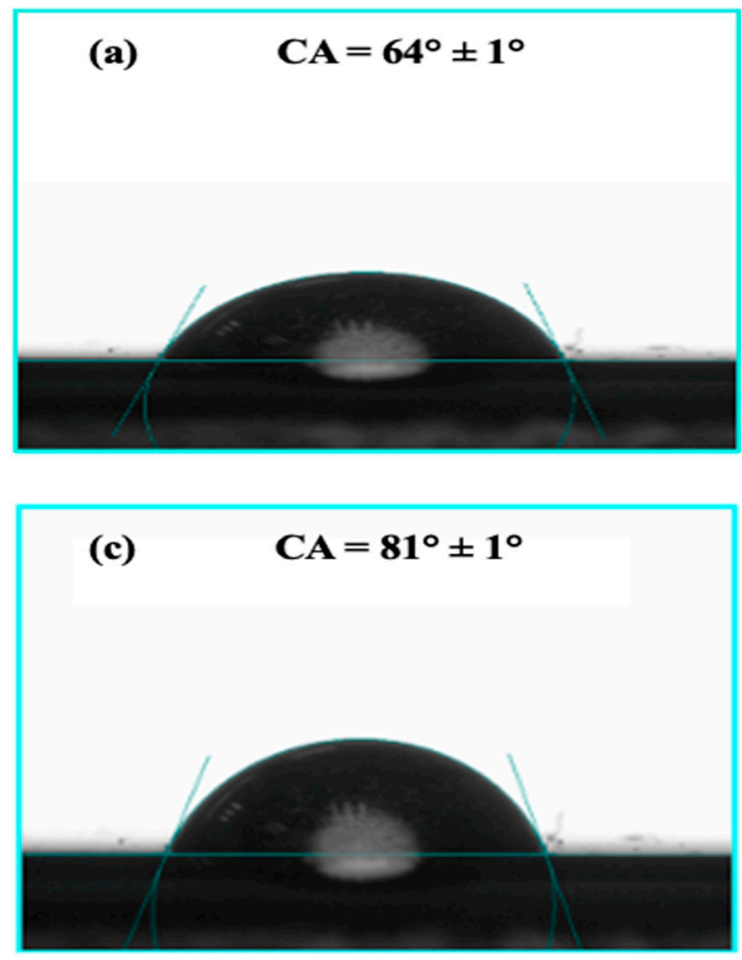
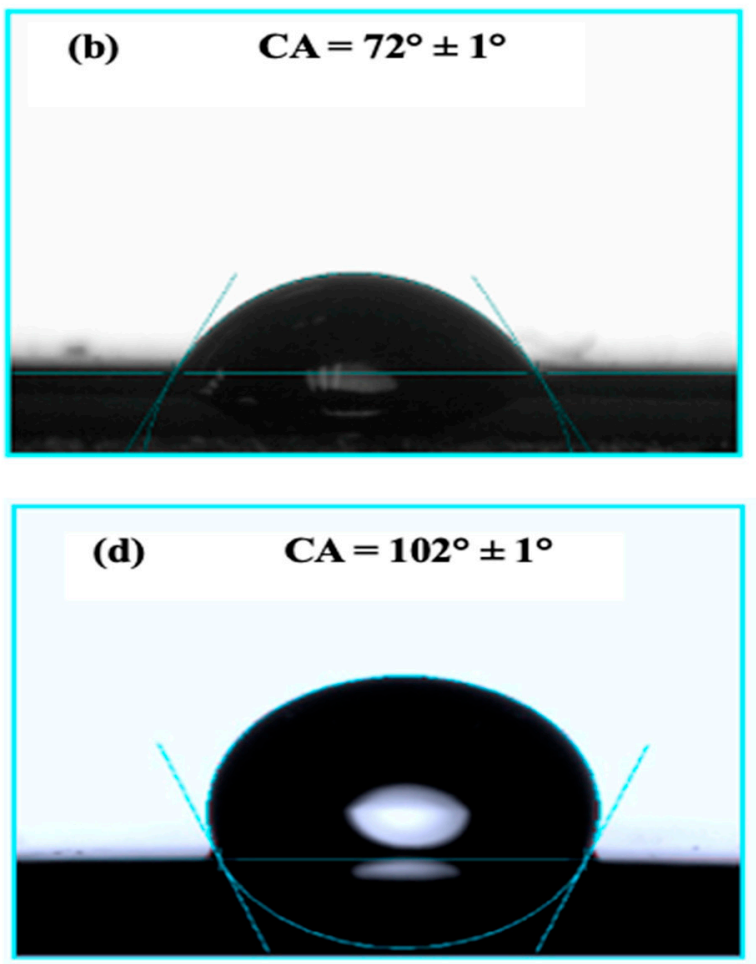

Figure 6. Surface contact angle of (a) neat epoxy, (b) X50 Gnp/epoxy, (c) M15 Gnp/epoxy, and (d) C750 Gnp/epoxy coatings.

\subsubsection{Water Absorption Testing}

Figure 7 shows the time dependence of the percentage of water uptake of the neat epoxy and Gnp/epoxy coatings after 15 days of immersion. The graph obtained can be interpreted in three stages. Firstly, the curves followed a rapid linear growth, rose up slowly with increasing immersion days until equilibrium was attained at the final stage [37]. The other characteristic parameter is the maximum absorbed water content when saturation is reached. The result is summarized in Table 3 for all studied samples. Comparatively, the time and degree of saturation for the composite coatings were not the same. C750 Gnp/epoxy showed a minimum water absorption percentage of $0.85 \%$, reaching equilibrium on the eighth day of immersion. For M15 Gnp/epoxy and X50 Gnp/epoxy coatings, the water absorption percentage of $0.94 \%$ and $1.21 \%$ were reached on the 10th and 11th day respectively. Neat epoxy reached equilibrium on the 13th day with $1.75 \%$ water absorption proving that the added Gnps reduced water permeability of the coatings by reducing the free volume and restriction of the molecular dynamics of epoxy's polymer chain segments as reported in previous study [38].

Table 3. Maximum absorbed water content \% of neat epoxy, and Gnps/epoxy composite coatings when saturation was reached.

\begin{tabular}{ccccc}
\hline Coating Samples & Neat epoxy & C750 Gnp & M15 Gnp & X50 Gnp \\
\hline $\begin{array}{c}\text { Maximum absorbed water } \\
\text { content } \%\end{array}$ & 1.751 & 0.851 & 0.946 & 1.213 \\
\hline
\end{tabular}




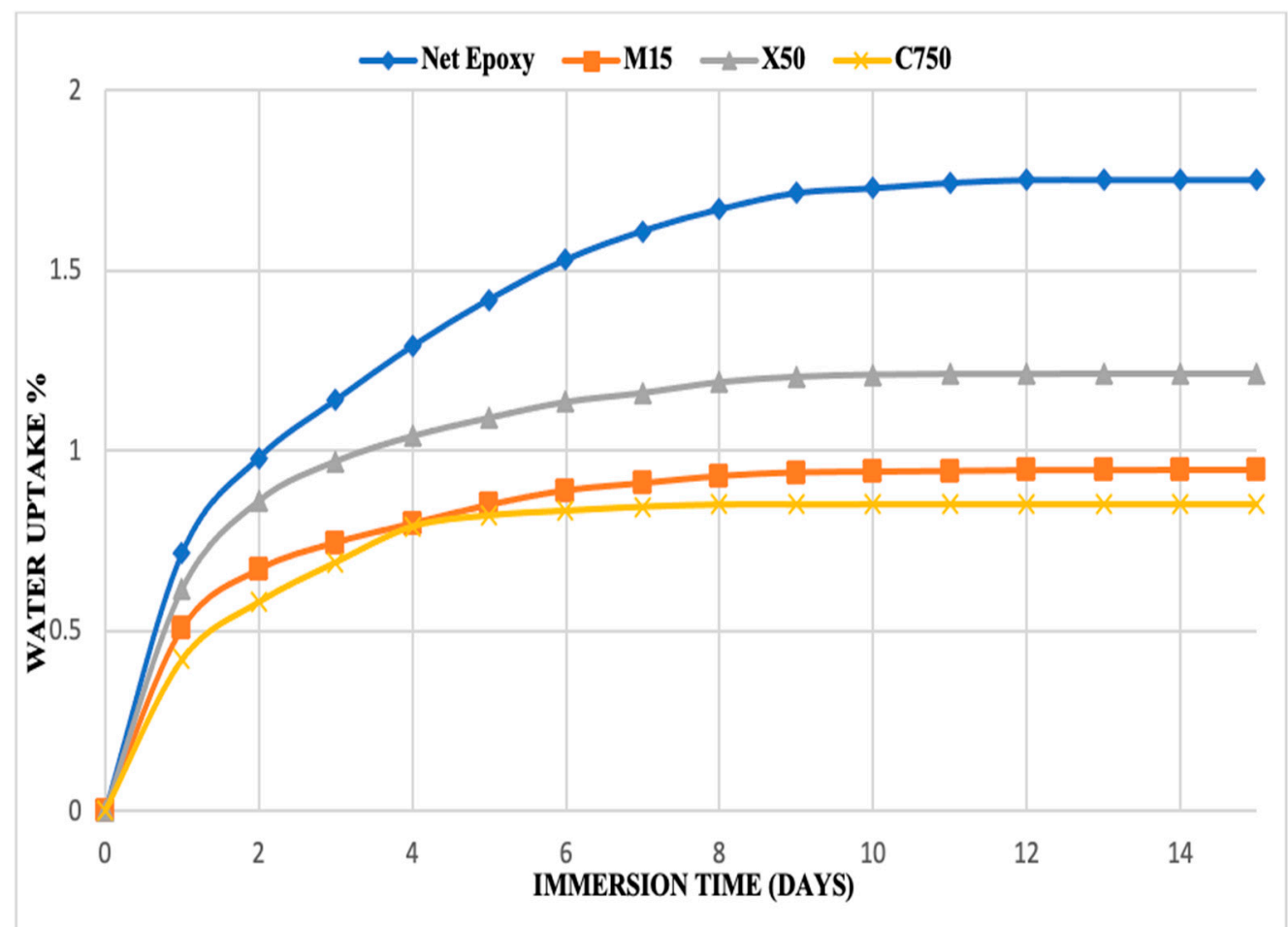

Figure 7. Time dependence of the percentage of water absorption in neat epoxy resin and epoxy composites reinforced with C750, M15, and X50 Gnps.

\subsection{Corrosion Properties of Gnps/Epoxy Composite Coatings \\ 3.3.1. Salt Spray Testing}

Neat epoxy and Gnps/epoxy coated samples were exposed to a salt spray of 5\% $\mathrm{NaCl}$ solution (based on ASTM B117) [31] for $750 \mathrm{~h}$. Figure 8 shows the optical images against time. From the results, formation of flower-like disbonded area appeared around the scratched area for neat epoxy, X50 Gnp/epoxy and M15 Gnp/epoxy coatings after $48 \mathrm{~h}$. It indicates the initiation of electrochemical reactions as corrosive ions diffused through the micro pores of neat epoxy matrix at the coating interface. Moreover, large blisters and brown-like discolored films were observed along the $\mathrm{X}$ scratched area which preceded to other parts of the surface of the neat epoxy coatings at the end of $750 \mathrm{~h}$. The added Gnps showed an improved corrosion resistance at different testing times. For instance, rusting became serious after $300 \mathrm{~h}$ of testing for X50 Gnp/epoxy and after $480 \mathrm{~h}$ of testing for M15 Gnp/epoxy coatings. Meanwhile, C750 Gnp/epoxy coatings experienced mild rusting as few small blisters were observed around the $\mathrm{X}$ cut area after $750 \mathrm{~h}$ of testing. Futher, there was no coating delamination proving that a strong interfacial bonding between C750 and the epoxy chains reduced brittleness, and hindered the diffusion of electrolyte. Table 4 shows the ranking of the coating failure after $750 \mathrm{~h}$ of salt spray testing according to ISO 4628-2 [32], which is used to assess the anti-corrosion performance of coatings. From the table, C750 Gnp/epoxy composite coatings showed an enhanced corrosion resistance compared to the M15, X50, and neat epoxy coatings. 


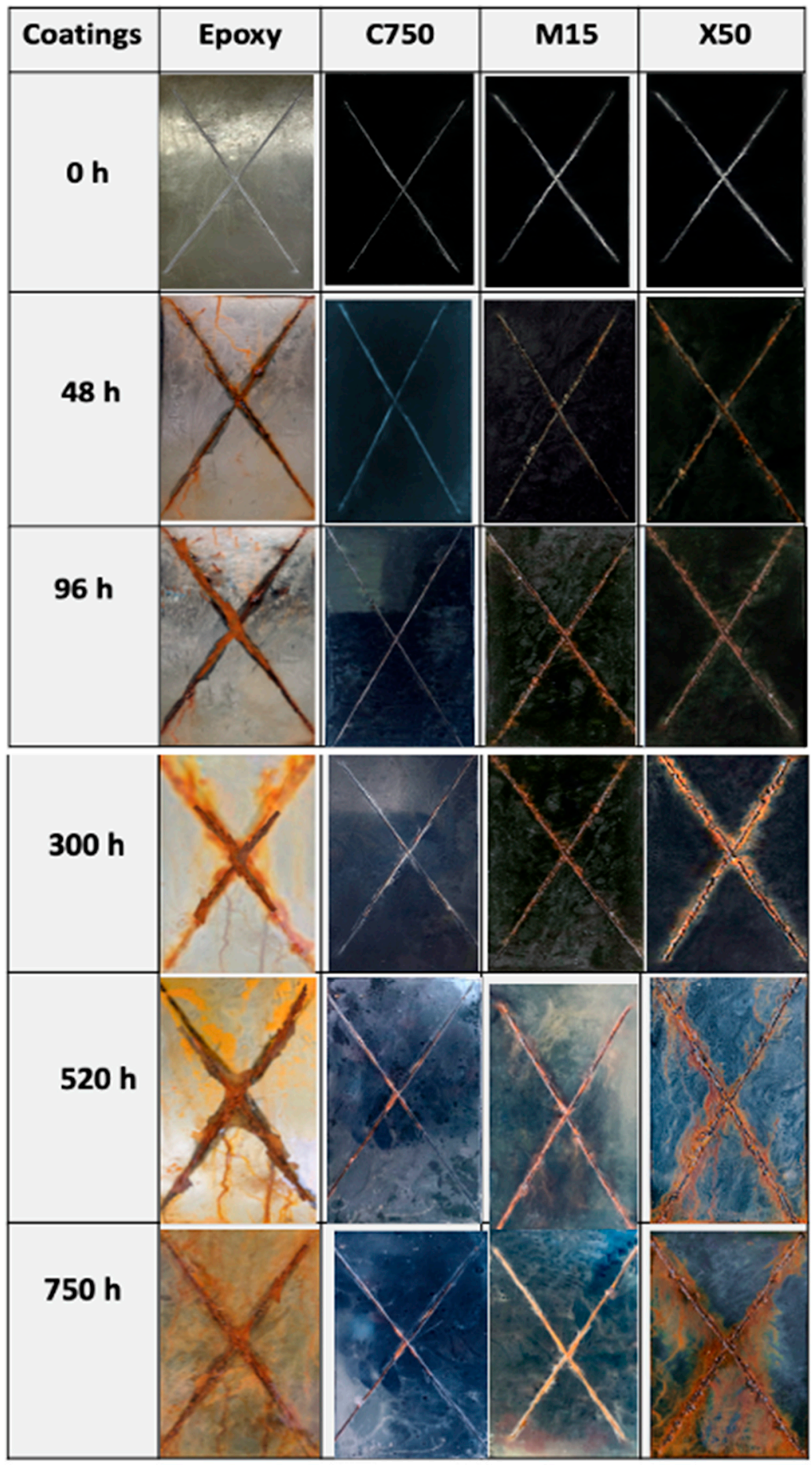

Figure 8. Optical images of neat epoxy and GNPs/epoxy coatings under salt spray testing against immersion time.

Table 4. Ranking of coating failure after $800 \mathrm{~h}$ of salt spray testing according to ISO 4628-2 [39].

\begin{tabular}{cccc}
\hline Coating Sample & Degree of Blistering & $\begin{array}{c}\text { Degree of } \\
\text { Blistering Size }\end{array}$ & $\begin{array}{c}\text { Degree of } \\
\text { Delamination }\end{array}$ \\
\hline Neat Epoxy & 5 & 5 & Severe \\
C750 Gnp/epoxy & 1 & 1 & Very Slight \\
M15 Gnp/epoxy & 2 & 2 & Slight \\
X50 Gnp/epoxy & 3 & 3 & Considerable \\
\hline
\end{tabular}




\subsubsection{EIS Characterization}

EIS analysis was further employed to investigate the corrosion resistance of the nanocomposite coatings. Figure 9 illustrates the Bode and phase angle plots and its equivalent Nyquist diagram for the neat epoxy and Gnps/epoxy coatings in $3.5 \% \mathrm{NaCl}$ solution. The curve appears as a one-time constant at the initial immersion stage and a two-time constant as penetration of corrosive media was initiated. The one-time constant is due to the capacitance impedance interaction with the coating interface that prevented corrosion process from taking place at the metal/coating interface. Generally, the lowfrequency end impedance modules and the high-frequency end phase angles of the Bode plots decreased with increasing immersion time for all coated samples. It is evident that the Gnps/epoxy coatings demonstrated excellent corrosion performance compared to the neat epoxy that exhibited a clear degradation by recording the lowest impedance and phase angle values after total immersion days. However, C750 Gnp/epoxy coatings (Figure $9 \mathrm{~g}, \mathrm{~h}$ ) maintained a maximum phase angle and impedance change from the low to the high-frequency range compared to the M15 and X50 coating samples (Figure 9c-f). A minimum in the phase angle corresponds to a plateau in the impedance modulus [40]. Figure 10 shows the impedance values at the lowest frequency (i.e., $|\mathrm{Z}| 0.01 \mathrm{~Hz}$ ) of the coated samples. C750 Gnp/epoxy exhibited a small drop in impedance at |Z I $0.01 \mathrm{~Hz}$ in the initial exposure times then increased after total immersion days. This was not witnessed in the other coatings where the drop values at $|\mathrm{Z}| 0.01 \mathrm{~Hz}$ between exposure times decreased rapidly. In addition, two schematic Models A and B equivalent to electrical circuits (Figure 11) were employed to suit the EIS data. The Alternating current (AC) impedance was used to establish the coating's capacitance and resistance to corrosion on the metallic substrate [41,42]. Model A represents a good corrosion resistance coating whiles Model B represents poor corrosion resistance coatings, where the model parameters are defined as follows: $R_{\mathrm{s}}$ is (solution resistance), $\mathrm{CPE}_{\mathrm{po}}$ is (Constant Phase Element) of the coating, $R_{\mathrm{c}}$ is the (coating resistance), $\mathrm{CPE}_{\mathrm{dl}}$ is (Constant Phase Element) of the double-charge layer and $R_{\mathrm{ct}}$ is (Charge transfer resistance) parameter [43]. The Bode plots of the neat epoxy compared to the Gnps/epoxy composite coatings (Figure 9) confirms the enhancing impact of Gnps in epoxy composites. Model A from the schematics corresponds with C750 Gnp/epoxy coating's EIS results illustrated in (Figure 9g,h) whilst Model B corresponds to M15 Gnp/epoxy, X50 Gnp/epoxy, and neat epoxy coatings EIS results (Figure 9a-f). This implies C750 Gnp offered an effective barrier protection hence enhanced the surface barrier performance of the composite coatings than the other Gnps.

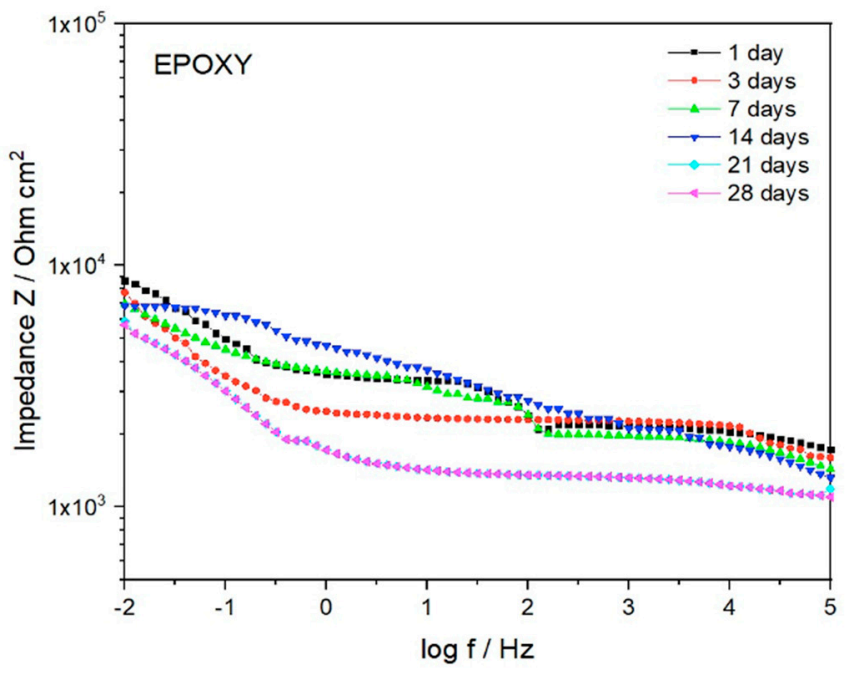

(a) Bode- $|\mathrm{Z}|$

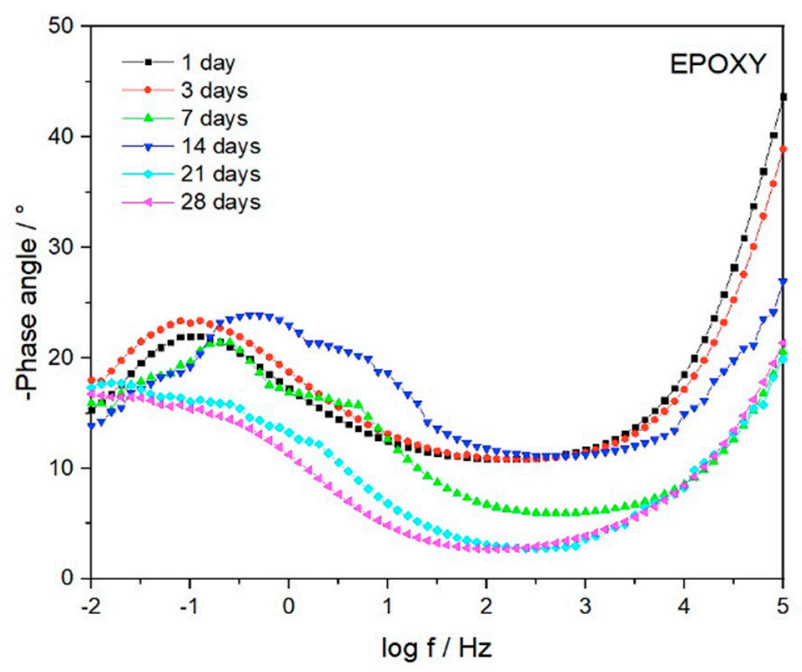

(b) Bode- $|\mathbf{P}|$

Figure 9. Cont. 


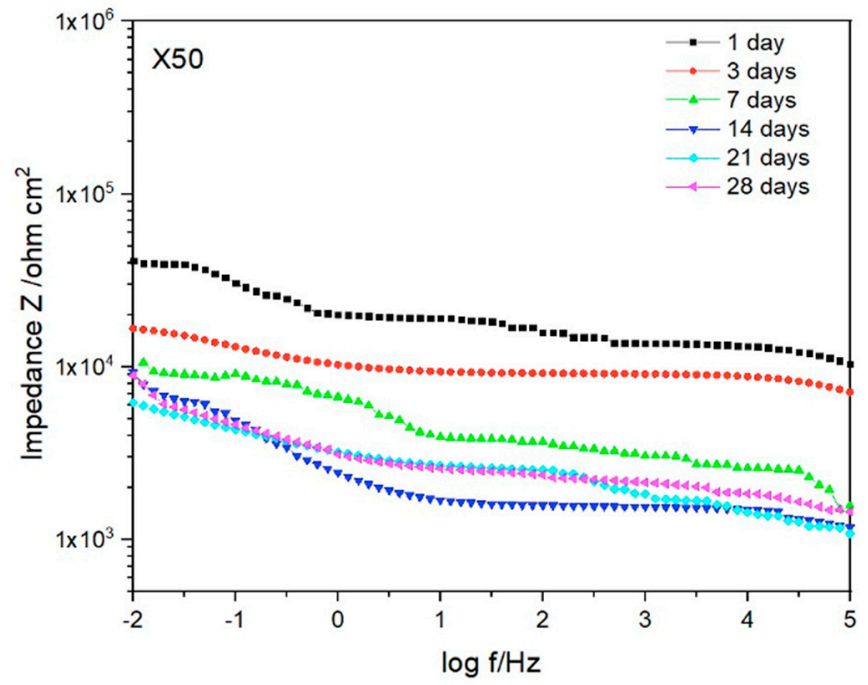

(c) Bode- $|\mathrm{Z}|$

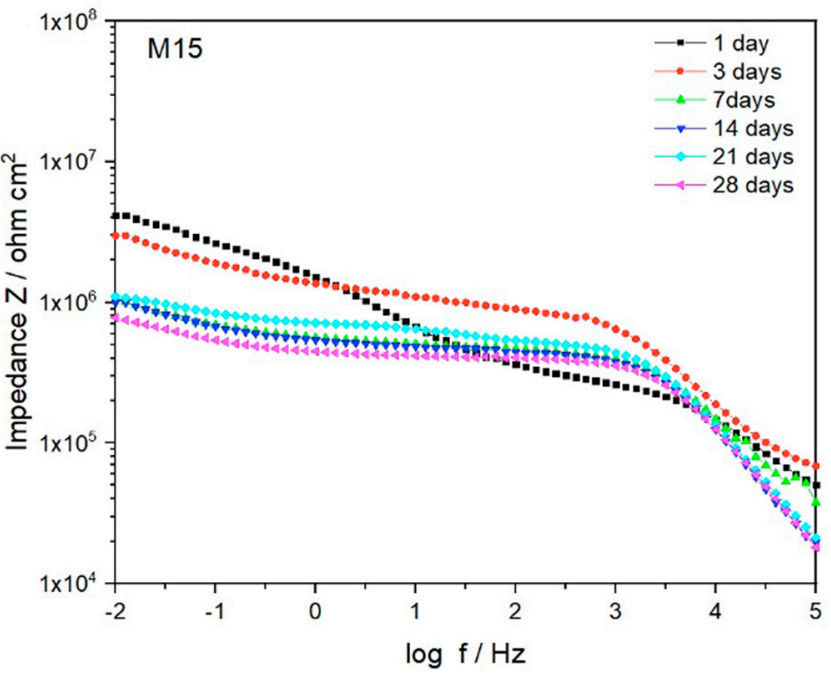

(e) Bode-|Z

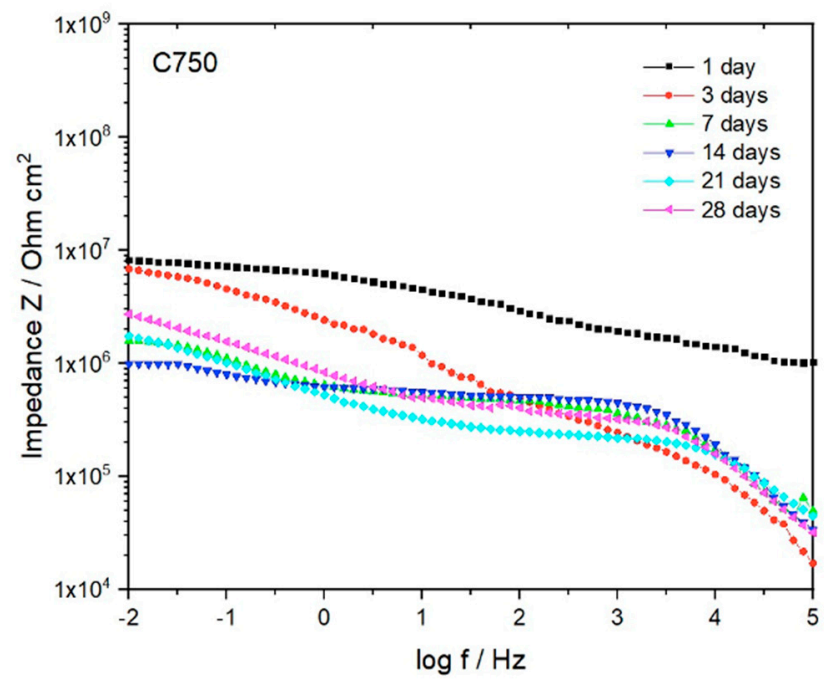

(g) Bode- $|\mathrm{Z}|$

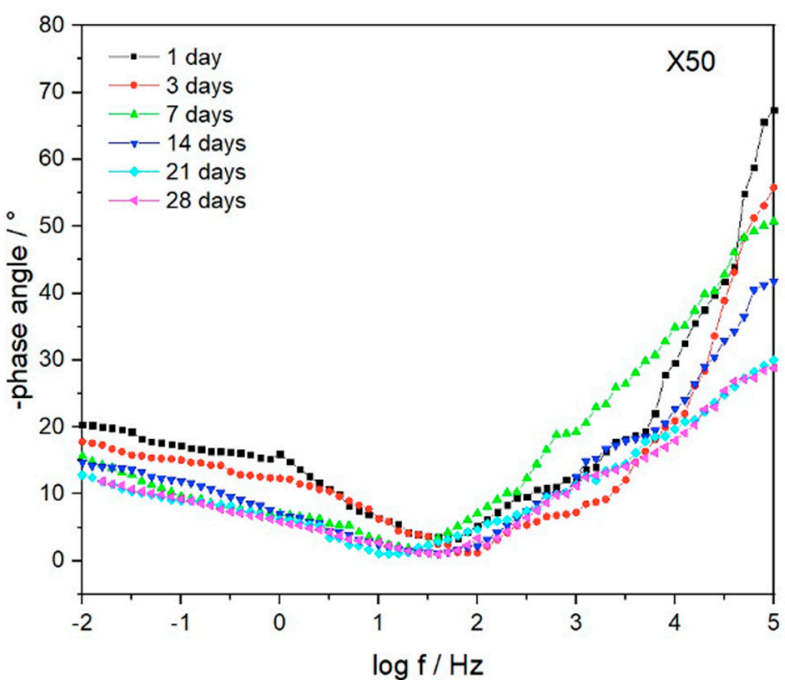

(d) Bode-|P|

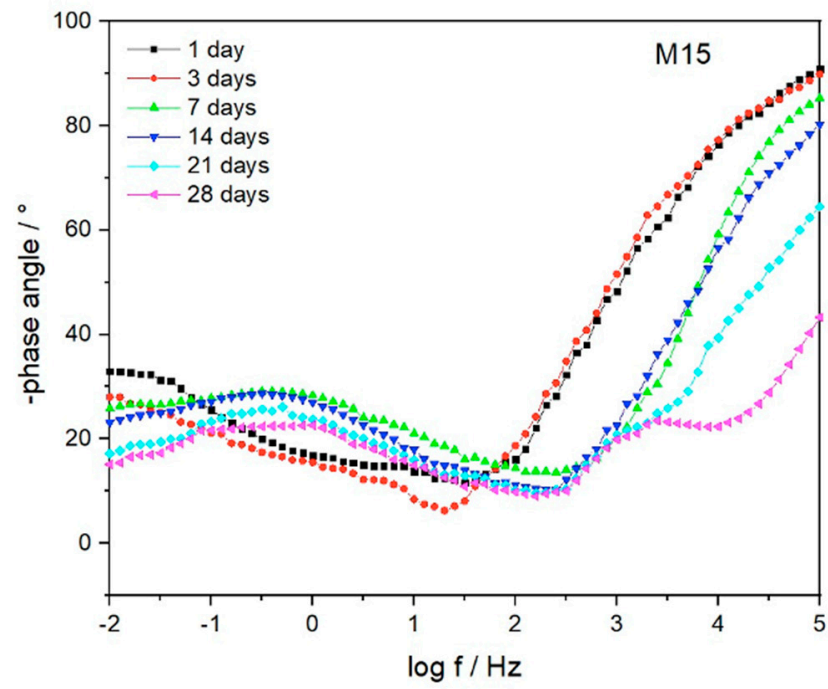

(f) Bode- $|\mathrm{P}|$

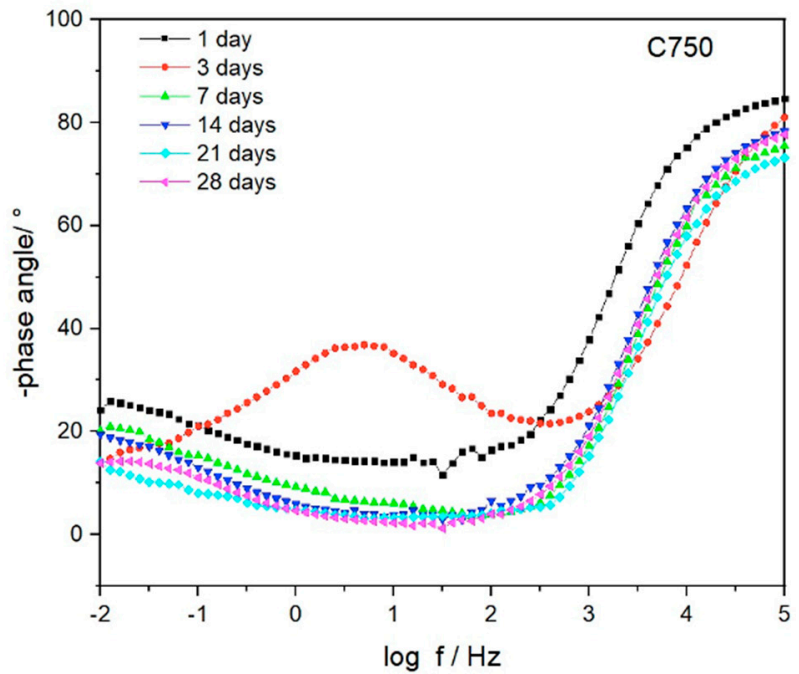

(h) Bode- $|\mathbf{P}|$

Figure 9. Cont. 


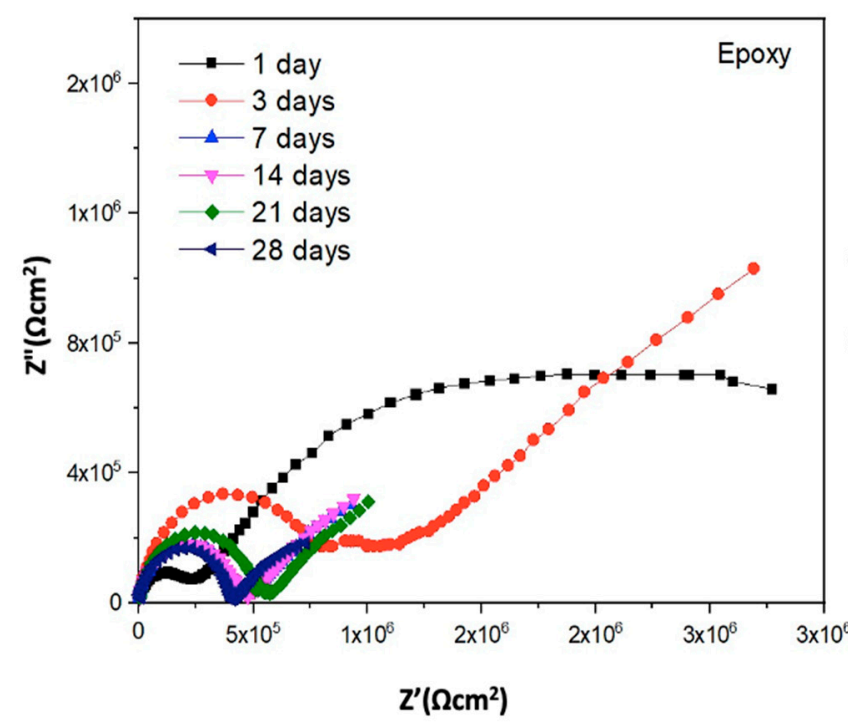

(i) Epoxy Nyquist

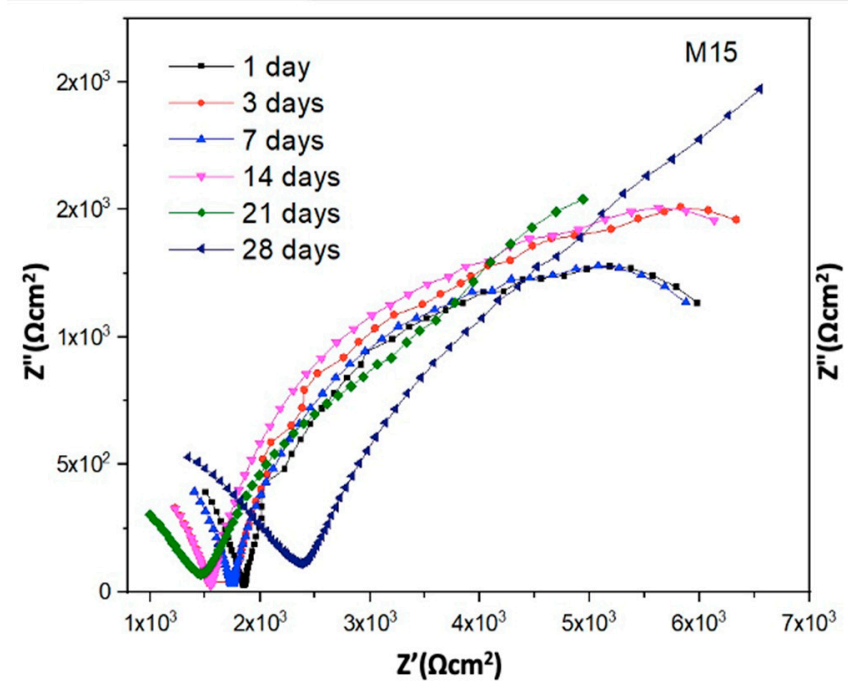

(k) M15 Nyquist

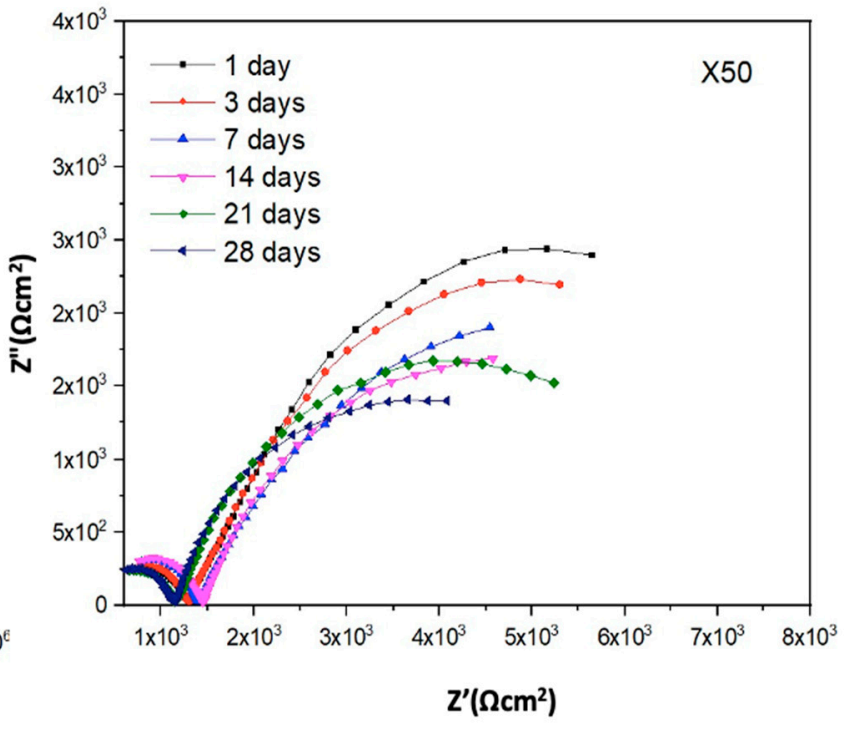

(j) X50 Nyquist

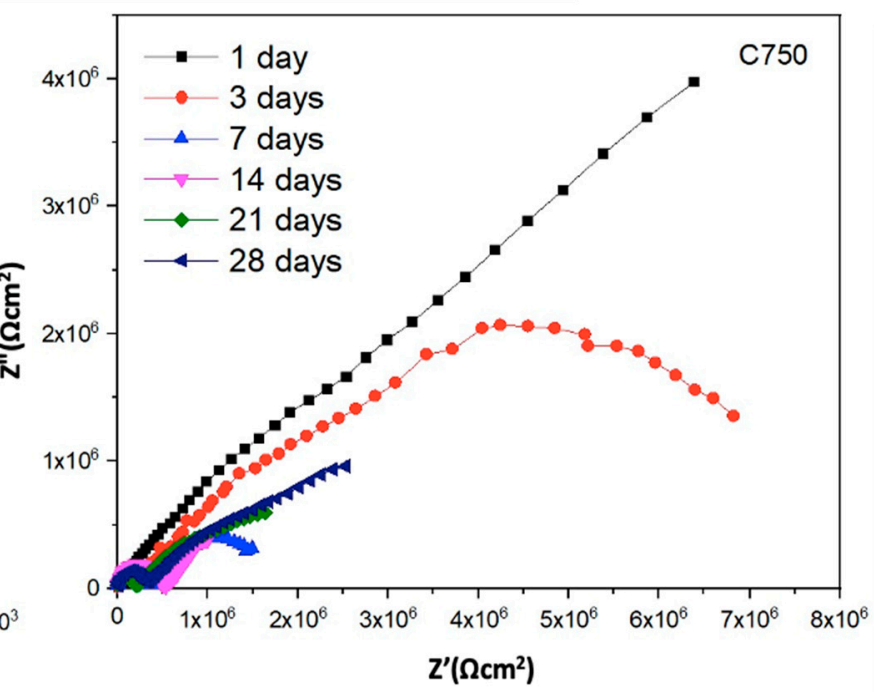

(l) C750 Nyquist

Figure 9. Bode plots of (a,b) neat epoxy, (c,d) X50 Gnp/epoxy, (e,f) M15 Gnp/epoxy, and (g,h) C750 Gnp/epoxy and Nyquist diagram of (i) neat epoxy, (j) X50 Gnp/epoxy, (k) M15 Gnp/epoxy, (l) C750 Gnp/epoxy coatings immersed in 3.5\% $\mathrm{NaCl}$ solution for different exposure time. 


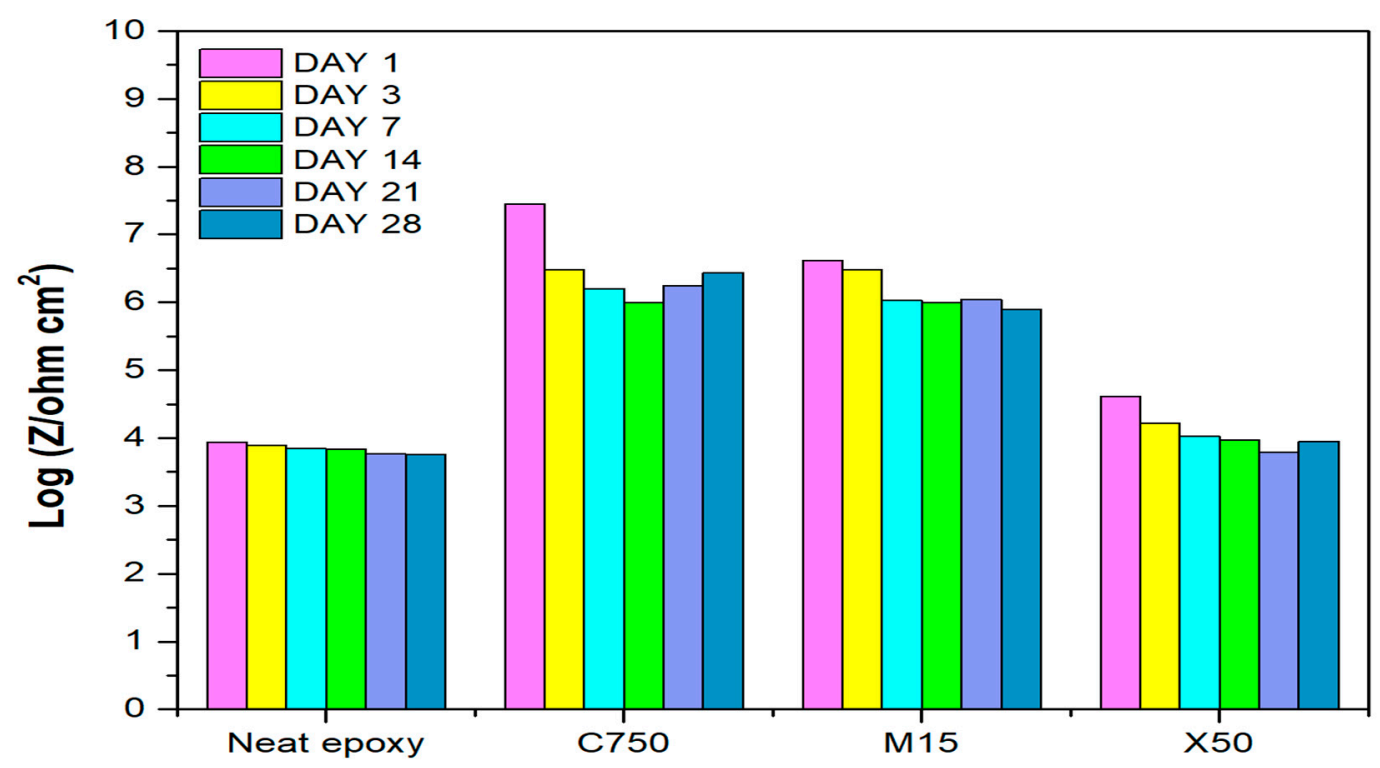

Figure 10. Impedance values at low Frequency end $(10 \mathrm{mHz})$ of prepared Gnp/epoxy composite coatings immersed in $3.5 \%$ $\mathrm{NaCl}$ solution at different Time.

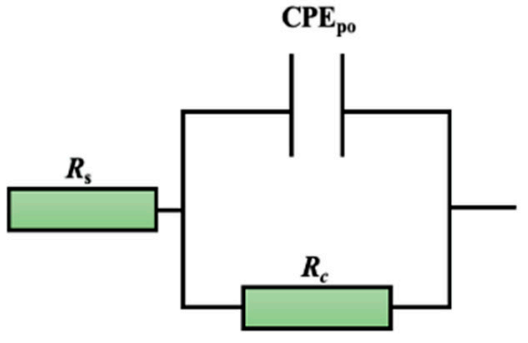

(a) Model A

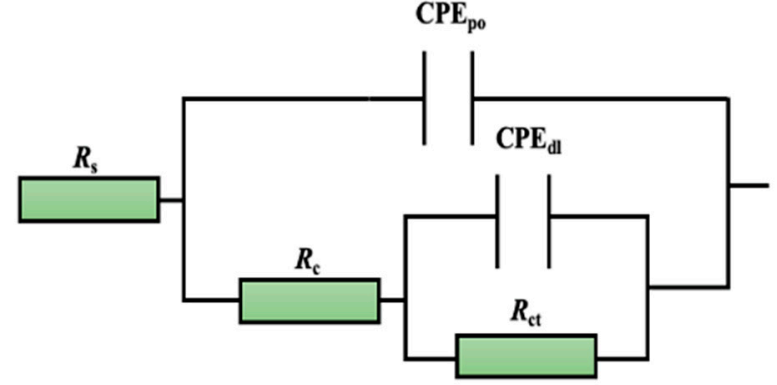

(b) Model B

Figure 11. Equivalent electrical models used for EIS data.

\section{Discussion}

\subsection{Morphological Influence on the Corrosion Properties of Gnps/Epoxy Composite Coatings}

The surface barrier protection and corrosion properties of the composite coatings in this study was principally influenced by two morphological features (particle size and specific surface area). Figure 12 depicts a schematic mechanism for the size effect of Gnps on the anti-corrosion performance of the Gnps/epoxy coatings. It is clear that, smaller Gnps (C750) are well-dispersed within the composites and provide more effective pathway to prevent diffusion of the corrosive agent. This extends the time taken for the corrosive agent to reach the metal substrate therefore providing a long-term anti corrosion protection. As confirmed in Figure 3, C750 Gnp of a smaller particle size experienced a better dispersion and fewer agglomeration in contrast to the other composites. This phenomenon observed could be caused by their intrinsic size difference. Comparatively, the larger size Gnps (M15 and X50) occupied a smaller domain in the epoxy matrix due to uneven dispersion that led to the formation of several aggregates in the composites, hence, offered a shorter route for the corrosion medium to reach the substrate under the same loading of Gnp weight. Homogeneous dispersion also enhances coatings absorption strength by reducing the amount of water molecules that penetrates into the coatings surface causing weaker links beneath the coatings thus decrease the coatings physical barrier qualities [44]. All those was confirmed by the water uptake results (Figure 7). Conjointly, smaller size Gnps 
do not only improve dispersion but also offers a high surface area which creates an efficient filler pathway to suppress corrosive attacks [33]. It is suggested that incorporation of a highly compatible nanoparticles of smaller particle size and high surface area improved the anti-corrosion performance of the coatings. This was in a good agreement with other reported studies $[5,26,45]$.

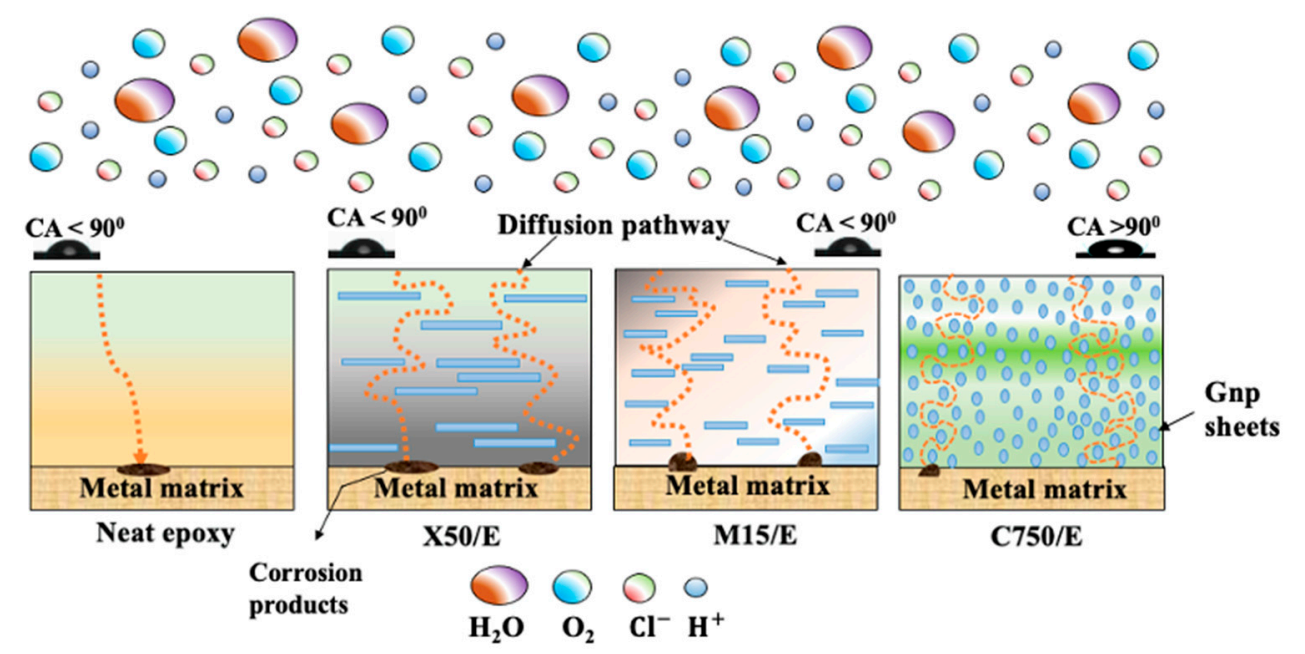

Figure 12. Schematic mechanism for enhanced anti-corrosion resistance of Gnps/epoxy composite coatings.

\subsection{Mechanism for Enhanced Anti-Corrosion Resistance of Gnps/Epoxy Composite Coatings}

Significant study of Gnps corrosion protection mechanism can be classified as follows: (i) the compatibility of Gnps with epoxy helps reduce the interface defects in the coatings, (ii) the high surface energy owing to nanomaterials system creates a highly hydrophobic nanocomposite coating surface, (iii) Gnps improve the bonding strength at the coatingmetal interface, and (iv) the impermeable nature of Gnps construct an excellent surface barrier against corrosive media by suppressing electrolyte pathways from the coating's surface to prolong corrosion occurrence [5,12]. A similar anti-corrosion mechanism trend was observed in our study as an improved anti-corrosion performance was exhibited by the coatings incorporated with Gnps compared to the neat epoxy coatings (Figure 12). Generally, addition of the three Gnps reduced the interfacial defects in the epoxy matrix by effectively filling the micro-pores and cracks formed during curing thereby reducing the water absorption of the coatings (Figure 8). Moreover, the Gnps improved the surface hydrophobicity (Figure 6) and interfacial bonding force resulting in high adhesion strength (Figure 5). Poor adhesion permits aggressive ions to accumulate at the coating/metal interface that leads to corrosion [43]. In addition, the Gnps/epoxy composite coatings exhibited a physical shielding effect as witnessed in the salt spray test results (Figure 8). The EIS study further demonstrated a higher resistance for the Gnps/epoxy coatings (Figure 9) by generating an impediment towards the ionic electrolyte, which enhanced the corrosion protection capability of the coatings. However, among all the Gnps/epoxy composite coatings, C750 Gnp/epoxy exhibited the most effective physical surface barrier performance which can be employed in corrosion protection fields whereas the other Gnps had a little contribution to the corrosion resistance of the composite coatings. The enhanced anti-corrosion mechanism observed by the C750 Gnps can be accredited to the homogeneous dispersion that promoted a less formation of agglomerates [46,47].

\section{Conclusions}

Three different types of commercial Gnps incorporated into epoxy matrix were evaluated for their capabilities as enhanced barrier protection coatings. The coating's overall performance, which consists of adhesion strength, hydrophobic nature, water absorption resistance and electrochemical properties were studied. The morphological impact of 
the Gnps on the anti-corrosion performance was specifically investigated with precise conclusions as highlighted below:

- C750 Gnp of a smaller particle size and higher average surface area were highly favorable to initiate an efficient pathway that strongly suppressed the deeper penetration of corrosive agents. On the contrary, when agglomeration occurred due to difficult dispersion caused by larger size Gnps (X50 and M15), the nanoparticles were unable to fill the micro pores and voids in the epoxy composites thus caused the coating's poor corrosion properties.

- The Gnps provided an excellent anti-corrosion mechanism by means of forming a passive protecting layer on the coating's interface that hindered with the diffusion rate of corrosive media like $\mathrm{O}_{2}, \mathrm{H}_{2} \mathrm{O}, \mathrm{H}^{+}$, and $\mathrm{Cl}^{-}$. However, the increased corrosion resistance of the Gnps/epoxy composite is attributed to the improved surface barrier's influence on the coating's anti-corrosion resistance and water uptake performance.

Author Contributions: Conceptualization, J.L., F.H. and R.R.A.; methodology, J.L., F.H., R.R.A., Y.W. and Q.H.; validation, J.L., F.H., R.R.A., Y.W. and Q.H.; formal analysis, J.L., F.H., R.R.A., Y.W. and Q.H.; writing—original draft preparation, F.H. and R.R.A.; writing-review and editing, J.L., F.H. and R.R.A.; supervision, J.L. All authors have read and agreed to the published version of the manuscript.

Funding: This research received no external funding.

Institutional Review Board Statement: Not applicable.

Informed Consent Statement: Not applicable.

Data Availability Statement: The data presented in this study are available on request from the corresponding author.

Acknowledgments: The authors in this work gratefully acknowledge the immense assistance offered by Wuhan University of Science and Technology, Wuhan, Hubei, China.

Conflicts of Interest: The authors declare no conflict of interest.

\section{References}

1. Ibrahim, M.; Kannan, K.; Parangusan, H.; Eldeib, S.; Shehata, O.; Ismail, M.; Zarandah, R.; Sadasivuni, K.K. Enhanced corrosion protection of epoxy/ZnO-NiO nanocomposite coatings on steel. Coatings 2020, 10, 783. [CrossRef]

2. Xavier, J.R. Investigation on the anticorrosion, adhesion and mechanical performance of epoxy nanocomposite coatings containing epoxy-silane treated nano- $\mathrm{MoO}_{3}$ on mild steel. J. Adhes. Sci. Technol. 2020, 34, 115-134. [CrossRef]

3. Zhou, X.; Huang, H.; Zhu, R.; Chen, R.; Sheng, X.; Xie, D.; Mei, Y. Green modification of graphene oxide with phytic acid and its application in anticorrosive water-borne epoxy coatings. Prog. Org. Coat. 2020, 143. [CrossRef]

4. Ammar, S.; Ramesh, K.; Ma, I.; Farah, Z.; Vengadaesvaran, B.; Ramesh, S.; Arof, A.K. Studies on $\mathrm{SiO}_{2}$-hybrid polymeric nanocomposite coatings with superior corrosion protection and hydrophobicity. Surf. Coat. Technol. 2017, 324, 536-545. [CrossRef]

5. Ramezanzadeh, B.; Haeri, Z.; Ramezanzadeh, M. A facile route of making silica nanoparticles-covered graphene oxide nanohybrids $\left(\mathrm{SiO}_{2}-\mathrm{GO}\right)$; fabrication of $\mathrm{SiO}_{2}-\mathrm{GO} /$ epoxy composite coating with superior barrier and corrosion protection performance. Chem. Eng. J. 2016, 303, 511-528. [CrossRef]

6. Golru, S.S.; Attar, M.M.; Ramezanzadeh, B. Studying the influence of nano- $\mathrm{Al}_{2} \mathrm{O}_{3}$ particles on the corrosion performance and hydrolytic degradation resistance of an epoxy/polyamide coating on AA-1050. Prog. Org. 2014, 77, 1391-1399. [CrossRef]

7. Işın, D.; Kayaman-Apohan, N.; Güngör, A. Preparation and characterization of UV-curable epoxy/silica nanocomposite coatings. Prog. Org. 2009, 65, 477-483. [CrossRef]

8. Ammar, S.; Cheng, C.H.; Ma, I.A.W.; Baig, S.B.; Kasi, R.; Subramaniam, R.; Balakrishnan, V. Effects of TiO 2 nanoparticles on the overall performance and corrosion protection ability of neat epoxy and PDMS modified epoxy coating systems. Front. Mater. 2020, 6, 336. [CrossRef]

9. Ramezanzadeh, B.; Attar, M. Studying the corrosion resistance and hydrolytic degradation of an epoxy coating containing ZnO nanoparticles. Mater. Chem. Phys. 2011, 13, 1208-1219. [CrossRef]

10. Dhoke, S.K.; Khanna, A.S. Effect of nano- $\mathrm{Fe}_{2} \mathrm{O}_{3}$ particles on the corrosion behavior of alkyd based waterborne coatings. Corros. Sci. 2009, 51, 6-20. [CrossRef]

11. Shi, H.; Liu, F.; Yang, L.; Han, E. Characterization of protective performance of epoxy reinforced with nanometer-sized TiO ${ }_{2}$ and $\mathrm{SiO}_{2}$. Prog. Org. Coat. 2008, 62, 359-368. [CrossRef]

12. Liu, D.; Zhao, W.; Liu, S.; Cen, Q.; Xue, Q. Comparative tribological and corrosion resistance properties of epoxy composite coatings reinforced with functionalized fullerene C60 and graphene. Surf. Coat. Technol. 2016, 286, 354-364. [CrossRef] 
13. Kumar, C.M.P.; Venkatesha, T.V.; Shabadi, R. Preparation and corrosion behavior of Ni and Ni-graphene composite coatings. Mater. Res. Bull. 2013, 48, 1477-1483. [CrossRef]

14. Pourhashem, S.; Vaezi, M.R.A.; Bagherzadeh, M.R. Exploring corrosion protection properties of solvent based epoxy-graphene oxide nanocomposite coatings on mild steel. Corros. Sci. 2016, 115, 78-92. [CrossRef]

15. Ramanathan, T.; Abdala, A.A.; Stankovich, S.; Dikin, D.A.; Herrera-Alonso, M.; Piner, R.D.; Adamson, D.H.; Schniepp, H.C.; Chen, X.; Ruoff, R.S.; et al. Functionalized graphene sheets for polymer nanocomposites. Nat. Nanotechnol. 2008, 3, 327-331. [CrossRef]

16. Glover, C.F.; Richards, C.; Baker, J.; Williams, G.; McMurray, H.N. In-coating graphene nano-platelets for environmentally-friendly corrosion protection of iron. Corros. Sci. 2017, 114, 169-172. [CrossRef]

17. King, J.A.; Klimek, D.R.; Miskioglu, I.; Odegard, G.M. Mechanical properties of graphene nanoplatelet/epoxy composites. J. Compos. Mater. 2014, 49, 659-668. [CrossRef]

18. Yadav, S.K.; Cho, J.W. Functionalized graphene nanoplatelets for enhanced mechanical and thermal properties of polyurethane nanocomposites. Appl. Surf. Sci. 2013, 266, 360-367. [CrossRef]

19. Kumar, A.M.; Khan, A.; Suleiman, R.; Qamar, M.; Saravanan, S.; Dafalla, H. Bifunctional CuO/TiO 2 nanocomposite as nanofiller for improved corrosion resistance and antibacterial protection. Prog. Org. Coat. 2018, 114, 9-18. [CrossRef]

20. Frigione, M.; Lettieri, M. Recent advances and trends of nanofilled/nanostructured epoxies. Materials 2020, 13, 3415. [CrossRef]

21. Monetta, T.; Acquesta, A.; Bellucci, F. Graphene/epoxy coating as multifunctional material for aircraft structures. Aerospace 2015, 2, 423-434. [CrossRef]

22. Prolongo, S.G.; Jiménez-Suárez, A.; Moriche, R.; Ureña, A. Influence of thickness and lateral size of graphene nanoplatelets on water uptake in epoxy/graphene nanocomposites. Appl. Sci. 2018, 8, 1550. [CrossRef]

23. Kuo, W.-S.; Tai, N.-H.; Chang, T.-W. Deformation and fracture in graphene nanosheets. Compos. Part A Appl. Sci. 2013 , 51, 56-61. [CrossRef]

24. Liu, S.; Gu, L.; Zhao, H.; Chen, J.; Yu, H. Corrosion resistance of graphene-reinforced waterborne epoxy coatings. J. Mater. Sci Technol. 2016, 32, 425-431. [CrossRef]

25. Starkova, O.; Buschhorn, S.T.; Mannov, E.; Schulte, K.; Aniskevich, A. Water transport in epoxy/MWCNT composites. Eur. Polym. J. 2013, 49, 2138-2148. [CrossRef]

26. Um, J.G.; Jun, Y.-S.; Alhumade, H.; Krithivasan, H.; Lui, G.; Yu, A. Investigation of the size effect of graphene nano-platelets (GnPs) on the anti-corrosion performance of polyurethane/GnP composites. RSC Adv. 2018, 8, 17091-17100. [CrossRef]

27. Ziat, Y.; Hammi, M.; Zarhri, Z.; Laghlimi, C. Epoxy coating modified with graphene: A promising composite against corrosion behavior of copper surface in marine media. J. Alloys Compd. 2020, 820. [CrossRef]

28. Q235B Chinese GB Standard Equivalent, Properties, Specification and Composition. Available online: https://www. theworldmaterials.com/chinese-gb-standard/ (accessed on 28 February 2021).

29. ASTM D4541-17, Standard Test Method for Pull-off Strength of Coatings Using Portable Adhesion Testers; ASTM International: West Conshohocken, PA, USA, 2017.

30. ASTM D7490-13, Standard Test Method for Measurement of the Surface Tension of Solid Coatings, Substrates and Pigments using Contact Angle Measurements; ASTM International: West Conshohocken, PA, USA, 2017.

31. ASTM B117-19, Standard Practice for Operating Salt Spray (Fog) Apparatus; ASTM International: West Conshohocken, PA, USA, 2019.

32. ISO 4628-1:2016, Paints and Varnishes-Evaluation of Degradation of Coatings-Designation of Quantity and Size of Defects, and of Intensity of Uniform Changes in Appearance-Part 1: General Introduction and Designation System; International Organization for Standardization: Geneva, Switzerland, 2016.

33. Cao, X.; Huang, F.; Huang, C.; Liu, J.; Cheng, Y.F. Preparation of graphene nanoplate added zinc-rich epoxy coatings for enhanced sacrificial anode-based corrosion protection. Corros. Sci. 2019, 159. [CrossRef]

34. Johnson, D.W.; Dobson, B.P.; Coleman, K.S. A manufacturing perspective on graphene dispersions. Curr. Opin. Colloid Interface Sci 2015, 20, 367-382. [CrossRef]

35. Naik, R.B.; Jagtap, S.B.; Ratna, D. Effect of carbon nanofillers on anticorrosive and physico-mechanical properties of hyperbranched urethane alkyd coatings. Prog. Org. Coat. 2015, 87, 28-35. [CrossRef]

36. Schniepp, H.C.; Li, J.-L.; McAllister, M.J.; Sai, H.; Herrera-Alonso, M.; Adamson, D.H.; Prud'homme, R.K.; Car, R.; Saville, D.A.; Aksay, I.A. Functionalized single graphene sheets derived from splitting graphite oxide. J. Phys. Chem. B 2006, 110, 8535-8539. [CrossRef]

37. Chen, C.; Qiu, S.; Cui, M.; Qin, S.; Yan, G.; Zhao, H.; Wang, L.; Xue, Q. Achieving high performance corrosion and wear resistant epoxy coatings via incorporation of noncovalent functionalized graphene. Carbon 2017, 114, 356-366. [CrossRef]

38. Salom, C.; Prolongo, M.G.; Toribio, A.; Martínez-Martínez, A.J.; Aguirre de Cárce, I.; Prolongo, S.G. Mechanical properties and adhesive behavior of epoxy-graphene nanocomposites. Int. J. Adhes Adhes 2018, 84, 119-125. [CrossRef]

39. Volovitch, P.; Vu, T.N.; Allély, C.; Abdel Aal, A.; Ogle, K. Understanding corrosion via corrosion product characterization: II. Role of alloying elements in improving the corrosion resistance of Zn-Al-Mg coatings on steel. Corros. Sci. 2011, 53, $2437-2445$. [CrossRef]

40. Jüttner, K. Electrochemical impedance spectroscopy (EIS) of corrosion process on inhomogeneous surfaces. Electrochim. Acta 1990, 35, 1501-1508. [CrossRef] 
41. Ghanbari, A.; Attar, M.M. A study on the anticorrosion performance of epoxy nanocomposite coatings containing epoxy-silane treated nano-silica on mild steel substrate. J. Ind. Eng. Chem. 2015, 23, 145-153. [CrossRef]

42. Wang, X.; Tang, F.; Qi, X.; Lin, Z. Mechanical, electrochemical, and durability behavior of graphene nano-platelet loaded epoxy-resin composite coatings. Compos. B Eng. 2019, 176. [CrossRef]

43. Parhizkar, N.; Ramezanzadeh, B.; Shahrabi, T. Corrosion protection and adhesion properties of the epoxy coating applied on the steel substrate pre-treated by a sol-gel based silane coating filled with amino and isocyanate silane functionalized graphene oxide nanosheets. Appl. Surf. Sci. 2018, 439, 45-59. [CrossRef]

44. Prolongo, S.G.; Gude, M.R.; Ureña, A. Water uptake of epoxy composites reinforced with carbon nanofillers. Compos. Part A Appl. Sci. Manuf. 2012, 43, 2169-2175. [CrossRef]

45. Qi, K.; Sun, Y.; Duan, H.; Guo, X. A corrosion-protective coating based on a solution-processable polymer-grafted graphene oxide nanocomposite. Corros. Sci. 2015, 98, 500-506. [CrossRef]

46. Dorri Moghadam, A.; Omran, E.; Menezes, P.L.; Rohatgi, P.K. Mechanical and tribological properties of self-lubricating metal matrix nanocomposites reinforced by carbon nanotubes (CNTs) and graphene-A review. Compos. B Eng. 2015, 77, 402-420. [CrossRef]

47. Montazeri, A.; Chitsazzadeh, M. Effect of sonication parameters on the mechanical properties of multi-walled carbon nanotube/epoxy composites. Mater. Des. 2014, 56, 500-508. [CrossRef] 